\title{
The Views of Health Workforce Managers on the Implementation of Workload Indicators of Staffing Need (WISN) Method in Primary Healthcare Settings in South Africa
}

\author{
Ntshengedzeni M Ravhengani ${ }^{1} \&$ Ntombifikile G Mtshali ${ }^{1}$ \\ ${ }^{1}$ School of Nursing and Public Health, Health Sciences, University of KwaZulu-Natal, Howard College, Durban, \\ South Africa \\ Correspondence: Ntshengedzeni M Ravhengani, PhD Candidate, School of Nursing and Public Health, Health \\ Sciences, University of KwaZulu-Natal, Howard College, Durban, 4000, South Africa.
}

Received: January 21, 2018

Accepted: March 13, 2018

Online Published: March 29, 2018

doi:10.20849/ijsn.v3i1.354

URL: https://doi.org/10.20849/ijsn.v3i1.354

This is part of a PhD project, which was sponsored by the Research Office of the College of Health Sciences at the University of KwaZulu-Natal.

\begin{abstract}
Background: Several African countries, including South Africa, are using the Workload Indicators of Staffing Need (WISN) method, as the preferred health workforce planning and management approach. Ineffective implementation of this method can however mean that health outcomes are not improved.

Objectives: This study explored the views of health workforce managers regarding potential barriers and enablers to implementation of the WISN method in South African primary healthcare (PHC) settings.

Method: This study adopted a qualitative approach and Grounded Theory research design. Following ethics clearance, a total of fourteen participants, PHC nurse managers and WISN coordinators were purposefully selected to participate in the study. Data were collected through focus group interviews and document analysis. Open, axial and selective coding was conducted to analyse data, including the use of Nvivo data analysis software to assist with the analysis.

Findings: Participants in this study highlighted a number of conditions necessary for the successful implementation of the WISN method. These included political will and leadership, provision of necessary support to enable implementation process, collaborative and consultative approach by stakeholders, clear, efficient and consistent communication, resources availability, continued support in implementing WISN and stability in leadership and staff in PHC settings.

Conclusions: The study concludes that successful WISN implementation requires addressing implementation barriers, such as unavailability of financial and human resources, and enhancing enablers, such as normative guides implementation guideline, technical capacity and availability of continuous support to implementers. This study's results can be used to enhance WISN implementation and health systems strengthening.
\end{abstract}

Keywords: workload indicators of staffing need (WISN), implementation, planning, health workforce manager's views

\section{Introduction}

In response to the growing demand for quality healthcare, health policy makers and human resources (HRH) managers in many countries are looking for opportunities to improve service delivery by adopting evidence based, efficient and effective planning and management approaches (World Health Organization, 2013; World Health Organization, 2016a). The Workload Indicators of Staffing Need (WISN) method, developed by the World Health Organization, is reportedly one of the tools that can assist countries in ensuring successful HWF planning and management, with minimal technical expertise (McQuide, Kolehmainen-Aitken, \& Forster, 2013; Namaganda, Oketcho, Maniple, \& Viadro, 2015; World Health Organization, 2010). A study conducted in 2016, regarding the experiences of few selected countries from the African Region in implementing Workload Indicators of Staffing Need (WISN) method, revealed there are several enablers and barriers that may affect 
successful implementation of this method (World Health Organization, 2016c). South Africa took a policy decision in 2012 to apply the WISN tool for health workforce planning in Primary Healthcare (PHC) settings, however, there is no appropriate evidence regarding the views of health workforce managers on WISN implementation enablers and barriers in PHC settings in the South African context. PHC settings were targeted because they are the first point of contact with healthcare for most patients (World Health Organization, 1978). This study therefore aimed to explore the views of the health workforce managers regarding the WISN implementation barriers and enablers of in PHC settings in South Africa.

\subsection{Background to the Study}

Universal health coverage (UHC) is becoming a key global health objective to ensure every citizen is guaranteed universally accessible primary healthcare (Puras, 2016). This is in line with the 1978 Alma-Ata Declaration and the Ottawa Charter, which established a bold plan for global health action and social justice, identifying primary healthcare as the cornerstone for achieving health for all (World Health Organization, 1978). There is also overwhelming evidence at the macro level (e.g., policy, finance, regulations), which shows that countries with a robust service for primary care have improved health outcomes at low cost (Rawaf, De Maeseneer, \& Starfield, 2008).

Responsible governance is crucial for meeting the needs and demands for healthcare provisions to all its citizens, by ensuring the health system is capable of delivering quality healthcare (Anand \& Bärnighausen, 2012), and that there are adequate resources and appropriate technical capacity to develop and implement new reforms required for health system strengthening (Dussault \& Dubois, 2003; World Health Organization, 2007). Several authors posit that lack of access to and use of planning methods and tools suitable for addressing the challenges facing many low and middle income countries across the world, is also responsible for critical health workforce shortages (Cometto \& Campbell, 2016; World Health Organization, 2006, 2007). However, HWF planning does not often receive adequate attention (Dussault \& Franceschini, 2006), stifling the reform agenda as well as the prospects of achieving equitable access to health services (World Health Organization, 2007) and improving health outcomes (Hongoro, Oliveira-Cruz, McPake, \& Ssengooba, 2004).

A paradigm shift to WISN-based health workforce planning is reported by a number of authors who cited the relationship between WISN implementation and health workforce planning reform, including improved healthcare outcomes (Burmen, Owuor, \& Mitei, 2017; McQuide et al., 2013; Namaganda et al., 2015). In addition, WISN introduction brings health workforce planning in line with the needs of the health sector in today's changing burden of disease (Cometto \& Witter, 2013; McQuide et al., 2013; Ravhengani \& Mtshali, 2017). Valente (2015) revealed that for successful adoption, implementation and sustainability of successful programmes, partnerships are vital (Valente, Palinkas, Czaja, Chu, \& Brown, 2015). Literature from the African region also confirmed that implementation of health workforce planning and management tools, such WISN, have been successful by ensuring stakeholders involvement in the WISN implementation process by focusing on team work (Musua et al., 2008; World Health Organization, 2016c). Furthermore, stakeholder involvement in the WISN implementation process promotes ownership and buy-in of the results (Vio, 2010), and they have positive outcomes in terms of improving health systems strengthening. However, literature review of health workforce planning, focusing on the African region, revealed that the implementation of WISN varied due to apparent diversity in application in different countries (World Health Organization, 2016c).

\subsection{Operational Definitions}

WISN: The World Health Organization (WHO) defines the Workload Indicators of Staffing Need (WISN) method as a human resource (HR) management tool, which provides health managers with a systematic way to make staffing decisions in order to plan and manage their valuable human resources well (World Health Organization, 2010).

Primary Healthcare Settings: In the context of this study, this refers to fixed primary care clinics and community health centres. The WHO posits that these health facilities offer essential healthcare, with the ultimate goal of ensuring better health for all (World Health Organization, 2015).

WISN Coordinator: In the context of this study, a WISN coordinator is an HR manager appointed by the Director General of Health Department for the coordination of the WISN implementation process at national level, provincial and district level.

PHC Nurse Manager: In the context of this study, this is a professional nurse appointed for the management of the PHC facility, also referred to as an Operational/Facility Manager. 


\section{Materials and Method}

This study adopted Strauss and Corbin's Grounded Theory research design and a qualitative approach (Strauss \& Corbin, 1990). A Grounded Theory approach was selected as it makes its greatest contribution in areas where minimal or no research has been undertaken and when new viewpoints are needed to describe the familiar phenomenon that is not clearly understood, specifically the adoption of innovations (Chenitz \& Swanson, 1986). Grounded Theory was deemed appropriate for this study, as it aimed to explore the views on an unfamiliar phenomenon-WISN method implementation barriers and enablers (Chenitz \& Swanson, 1986).

Fourteen purposively selected participants took part in the focus group interviews; five PHC nurse managers, and nine HR WISN coordinators who were involved in WISN implementation. Focus group interviews were found appropriate for this study as they encourage greater participation and stimulate those reluctant to share their views to contribute optimally to the discussion, as stated in Corbin and Strauss (2003). The focus groups were limited to a maximum of five members to encourage active participation. The researchers also opted for structured interviews to ensure greater consistency in the data collection between groups. The interviews were conducted in PHC settings, the participants' natural setting, and ranged between 45 minutes to one hour, depending on when the group reached saturation. Interviews were digitally recorded using an MP3 voice recorder.

Recorded interviews were listened to several times and transcribed verbatim. Three coding procedures, open, axial and selective coding, were followed (Corbin, Strauss, \& Strauss, 2014). Transcripts were read thoroughly line by line several times to get an overall sense of the content and meaning (Ravhengani \& Mtshali, 2017). Open coding involved breaking down of data leading to concept identification and included asking questions about data and making constant comparisons for similarities and differences between the emerging concepts; similar events and incidents were grouped as categories. Open coding, which was the initial phase of data analysis in this study, took place concurrently with data collection (Corbin et al., 2014). Axial coding allowed the researchers to assemble the data in new ways after open coding. The data was assembled and presented using a coding paradigm in which the researchers identified a central phenomenon, which was WISN implementation in this study. WISN implementation emerged as the main category, with categories and sub-categories supporting the main category. Selective coding involved the endorsing of one category as a core category and relating it in a systematic way to the other categories discovered in the study, around which the theory will eventually emerge. This phase included conducting a focused literature review to validate the emerging theory and story line (Corbin et al., 2014).

Trustworthiness: According to Creswell (2009), in qualitative research data findings must be trustworthy, reliable and reflective of the particular phenomena, which can be generalised to that specific study context (Creswell, 2009). In order to achieve scientific rigour, triangulation was done by utilising multiple sources of data, namely observation, document analysis and in depth individual interviews with participants (Polit \& Beck, 2012). To enhance internal validity of the study, data sources included policy makers and human resource managers from different levels-national, provincial and district level (Brink, 1993). Member checking (cross-checking) was conducted, filling of gaps and verification of concepts and categories that emerged from the data (Polit \& Beck, 2012). The researchers also went back to the participants to verify if the recorded data was accurate or needed elaboration; this was done to increase validity (Shenton, 2004). Bracketing strategy was also adopted to mitigate researchers' preconceptions when engaging with data and literature being used for comparison with emerging categories (Tufford \& Newman, 2012).

\subsection{Ethical Considerations}

Ethical clearance to conduct the study was obtained from the University of KwaZulu-Natal Humanities and Social Science Research Ethics Committee; protocol reference number HSS/2065/016D. All participants were informed about the purpose of the study and their rights. Informed consent was obtained from the participants before their participation in face-to-face interviews. Participation was voluntary and gathered data was treated with confidentiality, with code numbers used to ensure anonymity. Participants' permission was also sought to allow audio recording of interviews. Raw data and transcripts were stored in secure storage, only accessible to the researchers.

\section{Findings}

In this study, six categories emerged under intervening conditions, which acted as enablers or constraints to the implementation of the WISN method in PHC settings. The categories included (a) Political will and leadership, (b) Provision of necessary enablers, (c) A collaborative and consultative approach by key partners and stakeholders, (d) Clear, efficient and consistent communication, (e) Resources availability (financial and human) 
and (f) Stability in leadership and PHC staff.

\subsection{Political Will and Leadership}

Political leadership and good political will by those at strategic levels, the National Department of Health, Provincial Department of Health, Districts and local level, to actively support and implement WISN were cited as significant contributors to successful implementation of this method. According to the participants, the directive to adopt an approach that will ensure consistency in HRH Planning across the country, increase healthcare services accessibility and the inequitable distribution was from the Minister of Health, supported by the members of the National Health Council (NHC). The WISN method's implementation was managed as a National Department of Health programme, working in collaboration and partnership with leadership in Provinces and Districts of Health and this was perceived as one of the conditions that facilitated its successful implementation.

"I believe that WISN implementation has been made successful in South Africa because there has been political will to begin the process of change from traditional health workforce planning to a unified evidence based approach, at all spheres of government, from national, provincial, district including the local government."

"WISN is the National Department of Health project led by the Minister of Health, supported by the Director General (DG) for Health, the Members of Executive Council (MECS) for Health and their Heads of Health Departments (HODs) from all Provinces in the country. The MECs and their HODs work closely with District Health System leadership because that is where WISN is implemented. In my view, having leadership from the highest level to the District level is essential for successful implementation of WISN."

"We got officially appointment by the DG for Health as National and Provincial WISN coordinators to facilitate WISN implementation across provinces, after the adoption of the WISN method by the NHC ... Provincial HODs also appointed the WISN implementation groups including the District WISN champions to facilitate WISN implementation at District and local levels, supported by both the National and Provincial WISN coordinators... we also reported progress in WISN implementation to the NHC and the Departmental executive meeting regularly."

\subsection{Provision of Enablers}

Data sources revealed that the National Department of Health provided a number of enablers to ensure successful implementation of WISM method in the country. The enablers, which emerged as sub-categories under this category, included normative guides and standards implementation guideline, building technical capacity to implement HRH planning reform and availability of continuous support to WISN implementers.

3.2.1 Normative Guides and Standards Implementation Guideline

According to the data sources, the Minister of Health gazetted the PHC normative guides and standards implementation guideline in 2015, which provided the legal framework to guide the implementation of the WISN method in HRH planning in the country.

"In 2015, the government gazetted WISN-based PHC health workforce normative guides and standards implementation guideline to facilitate HRH planning and management at the South African fixed PHC facilities in line with the PHC package of services."

"The PHC normative guides provide a guiding process in determining staffing needs in a standardised and consistent manner across all provinces."

\subsubsection{Building Technical Capacity to Implement HRH Planning Reform}

Data sources revealed that building the capacity of the trainers and PHC nurse managers who were involved in WISN implementation was crucial for the success of WISN. The core team, which comprised of a National WISN team and Provincial WISN coordinators who were going to serve as trainers in their different provinces, received training that was facilitated by WISN experts from the World Health Organization. The five-day training covered a range of areas, including the WISN concept and methodology, WISN implementing processes, determining priority for WISN implementation, WISN calculations using manual and WISN software, as well as setting up a WISN implementation committees, which included the Technical Task Force and Expert groups and the steering committee. The participants reported that the training was very intensive and hands-on, building their capacity in implementing the WISN method in their facilities.

"Our WISN method training team consisted of World Health Organization (WHO) health systems 
strengthening experts from the Regional Office for Africa, and Headquarters... National Department of Health had a five days' WISN Trainer of Trainers (TOT) workshop in Pretoria. This training exposed us to the WISN tool and how this method can be applied in real practice."

"The purpose of the training offered by the WHO experts was to ensure that the National team would be competent in the WISN tool application, in order to train others across the country... The training equipped trainers on strengths and limitations of the WISN concept and methodology...WISN calculations using WISN software and manually, practiced intensively, reiterating and emphasising the importance of using accurate data when determining staffing requirements. "[Document analysis]

3.2.3 Availability of Continuous Support to WISN Implementers

Availability of continuous provision of technical support served as an enabler for WISN implementation in South Africa. Continuous technical support was provided by WHO experts to ensure that the country could implement the WISN method effectively. WISN coordinators and PEPFAR supported developmental partners, those who provided continuous technical support to provinces as they were applying WISN, in determining the staffing needs to ensure consistency in the application of this method, as per the excerpts below.

"The WHO staff provided continuous support to the Department of Health in the process of training provincial teams and implementing WISN, and in generating staffing norms and standards."

"Our WISN implementation processes have been facilitated through continuous technical support received from the WHO experts and the WISN coordinators as well as the developmental partners who helped us with the training process including provision of print materials."

"We have had for the past three years HR provincial technical officers appointed to support us in WISN implementation in our province with the financial resources arranged by the National Department of Health."

The PHC nurse managers working in rural and remote areas reflected that they were confident about the application of the WISN method independently, due to the additional capacity building support they received. Participants reflected that the supplementary training they received, in the workshop setting and in their facility settings, contributed to improving their confidence in WISN implementation; once off training would not have been enough.

"I believe that the WISN implementation training we received both at the workshop and a facility level have been more meaningful and effective because it was interactive and in my workplace setting..."

Data sources revealed that those at facility level felt inadequately prepared to use the computer for determining staffing requirements because of perceived lack of computer skills. The participants cited this as a major setback because the PHC nurse managers, for example, had to learn these new technical skills (using Excel spread sheet and using the WISN software), whilst having to deal with huge numbers of patients, as one participant stated:

"I last touched a computer during the WISN training workshop... I feel that there should be continuous support to us who are not used to working with computers."

"I believe it will be difficult to change to WISN based health workforce planning, because using a computer is still a challenge for me."

\subsection{A Collaborative and Consultative Approach by Key Partners and Stakeholders}

Closer collaboration between the National Department of Health, provincial WISN coordinators, PHC nurse managers, the World Health Organization (WHO) experts, labour organisations and developmental partners in supporting PHC facility staff emerged as one of the critical conditions that determined the successful implementation of WISN and sustainability of the programme.

"We consulted widely from various levels through numerous dialogues and networking with all key stakeholders, including engagement of labour organisations for the purpose of achieving accepted outcomes... this made it easy to get their support for WISN implementation."

"Decisions were taken collaboratively with all relevant stakeholders with regards to determining staff requirement in different PHC settings, overstaffed and understaffed PHC settings based on facility workload pressure, and the need to develop a strategy for redistribution of excess staff...Organised labour had to be involved in the WISN implementation process to as early as possible so as to ensure their buy-in..."

Conversely, some participants reflected on the concerns raised by labour organisations regarding broader 
consultation with health workforces at the coalface. These participants expressed lack of broader consultation regarding the need for the WISN Tool utilisation with the people actually doing the job. Although the PHC nurse managers were trained on WISN-based health workforce planning, it emerged from this study's findings that professional nurses and other health workforces at facility levels had been left out, as indicated in the quotation below:

"I believe that the Department should have engaged all the health workers at a facility level regarding WISN implementation instead of focusing only at health workforce mangers and the representatives of labour organisations, because they too are required to use this tool to improve health outcomes."

\subsection{Clear, Efficient and Consistent Communication}

The need for clear, efficient and consistent communication from national level, to provincial, district and PHC facility level emerged as important in the process of implementing WISN. This was to ensure communication of a common message across the provinces and at different levels of the healthcare system, facilitating consistency in decision-making and avoiding unnecessary confusion and assumption of different HRH planning methodologies.

“... There is a clear communication strategy informed by the PHC normative guides and standards implementation guideline helping us to share information on WISN implementation effectively nationally...the Guideline also indicates clear steps, including the roles and responsibilities of managers in WISN implementation in all levels of government from the DG of Health to an operational manager at a PHC facility level. "[Document analysis]

"Realising that it can be difficult to share information all of the time with all partners, we have disseminated the PHC normative guides implementation guideline to all stakeholders because we believe that there is a need to ensure that every health worker understands the WISN implementation goal and their role in WISN implementation at PHC settings ... to avoid confusion when making staffing decisions which could be attributed due conflicting messages."

\subsection{Resources Availability (Financial and Human)}

It emerged from data sources that successful implementation of WISN depended on the availability of resources, financial, human and material. The participants perceived implementation of WISN to have high cost implications because additional staff have to be appointed to fill the staffing gaps and ensure balanced skills mix in PHC facilities. Participants also reflected about the need for incentives to attract and retain staff, particularly in remote and rural areas. Participants stated that WISN introduction would be impossible because their provinces had frozen all posts that were not critical, due to financial constraints.

“... For WISN to be implemented successfully the Department will require additional funding to ensure adequate HRH and balanced skills mix in our clinics, and there has to be incentives for those HRH personnel placed in rural and remote PHC settings"

"In my view WISN implementation is expensive, when I check our current budget it shows that we will not be able to fund the posts determined based on the WISN tool."

"Budgetary constraints will make it difficult to implement WISN, as in our Province post have been frozen, we are only appointing clinical professional staff in critical positions, not non-clinical staff."

\subsection{Stability in Leadership and PHC Staff}

Stability of leadership and low staff turnover emerged as important conditions in successful implementation of WISN. The participants expressed concerns about the high turnover of those in leadership positions, who initiated and supported the adoption of the WISN tool, because new leaders have other priorities and different agenda. Other participants expressed concerns over high numbers of retiring and resigning staff in PHC settings, who are not replaced due to financial constraints and a moratorium on filling vacant positions. This in their view, in the absence of the sustainability plan, reverses the efforts made to plan and allocate HR according to the required skill mix in the PHC settings.

"High leadership turnover makes it difficult to follow through the change introduced...For example; in our Province we have lost two HODs already who were part of WISN introduction. We have also lost a number of staff at Provincial level, District level and some at Facility levels, including the WISN coordinators..."

“... People thought WISN was going to solve the problems of staff in PHC settings but there is no sustainability plan in the current context of our healthcare system with limited resources. The people 
who were appointed, both clinical and non-clinical staff, resigned or retired are not replaced due to the moratorium placed on filling of vacant posts... this I believe will affect sustainability of WISN implementation in our province."

\section{Discussion}

Our study findings demonstrated that focusing on conditions which enabled or constrained implementation of the WISN approach could provide a suitable structure for successful WISN implementation in PHC settings in South Africa. Analysis demonstrated that a number of issues needed to be addressed to ensure successful implementation of the WISN method. Overarching views or beliefs that might pose as barriers or enablers to implementation of the WISN approach to HRH planning and management were identified within the six categories and included political will and leadership, provision of necessary enablers, a collaborative and consultative approach by key partners and stakeholders, clear, efficient and consistent communication, resources availability (financial and human) and stability in leadership and PHC staff.

The value of political will and leadership commitment in successful programme implementation in healthcare settings has been demonstrated both nationally and internationally (Dussault, Buchan, Sermeus, \& Padaiga, 2010; Gilson, 2016). It would appear the successful implementation may be attributed to political leaders who see to it that a policy for which they publicly advocated actually gets implemented on the ground and ensuring that WISN-based health workforce planning contributes towards improved healthcare outcomes (World Health Organization, 2016c). Conversely, since governments are stewards, or protectors, of the public interest, the political will and leadership assists in ensuring that implementation of HRH activities, such as the WISN approach, receives the adequate attention it deserves (Cometto \& Campbell, 2016; Omaswa \& Boufford, 2010). It also helps in advancing the transformation agenda towards evidence based HWF planning, the vision of achieving equitable access to health services (Hongoro \& McPake, 2004; World Health Organization, 2007), the National Health Insurance (NHI) Policy implemented towards achieving Universal Health Coverage (UHC) in South Africa and Ideal Clinic Realisation and Maintenance (Department of Health, 2017; Jeanette R Hunter, 2017). Additionally, the Minister of Health together with the members of the National Health Council (NHC), i.e. provincial Members of Executive Council (MEC)s, Heads of Health (HODs) and appropriate key stakeholders, have a responsibility to determine what will enhance the health system's strengthening (Department of Health, 2003); this would include adoption of the WISN tool for health workforce planning and management in South Africa.

It emerged from this study that following the adoption of the WISN method by the NHC, the DG for Health, South Africa, appointed a National WISN coordinator and provincial WISN coordinators tasked with the responsibility of implementing the WISN tool across the country and reporting directly to the NHC and other Departmental executive management meetings regularly. Subsequent to that, the HODs appointed the provincial WISN implementation groups, including the District WISN champions, to ensure effective implementation of the WISN method at provincial and district levels, as indicated by participants. This was supported by a study conducted in Namibia, which revealed that successful WISN implementation was facilitated by establishing a task team with clear roles and responsibilities, with well-defined timelines, outputs/outcomes and reporting structures, reporting directly to the Permanent Secretary and providing monthly updates to a national restructuring committee (McQuide et al., 2013). In Uganda however, successful implementation of the WISN method was hampered by limited ownership and stewardship from the leadership (Namaganda et al., 2015).

Participants demonstrated an inherent inclination towards a collaborative and consultative approach by key partners and stakeholders in WISN implementation working at the coalface, including categories such as professional nurses and other support staff not in management positions. This could enhance buy-in received, team work and envisaged sustainability (Valente et al., 2015). These beliefs are in line with studies conducted in the African region, which regard involving key stakeholders from the start in any WISN exercise as the most important part of the WISN implementation process, because it increases ownership and acceptability of the study results (Govule et al., 2015; Musua et al., 2008).

The study findings further revealed the importance of ensuring clear, efficient and consistent communication. This supported a local study that emphasised the importance of ensuring that implementation of programmes are well coordinated and organised (Mtshali, 2009) to ensure a well-motivated health workforce (Hongoro et al., 2004). Paying attention to techniques such as information provision and communication of non-conflicting messages, which could be facilitated through workshops to inform or update HRH on the synthesised evidence and subsequent recommendations related to WISN implementation, could result in successful implementation (Snyder, Hamilton, \& Hornik, 2002). The variation in applying the WISN approach demonstrated between the 
individual health professional groups in different countries, which was also experienced in South Africa, potentially identifies the need for any interventions to include all members of the multi-disciplinary team to accommodate discussion of the WISN implementation methodology (World Health Organization, 2016c). The 2015-2019 Implementation guideline of health workforce normative guides and standards for fixed PHC facilities, gazetted by DOH in 2015, developed based on the WISN approach, could be used to address conflicting messages (Department of Health, 2015). That said, the South African DOH could draw valuable lessons from the Ugandan WISN implementation approach to ensure sustainability of the programme, wherein the country managed to institutionalise WISN training within the country's Master's-level health service management degree programme, which guaranteed a steady supply of managers well educated about the WISN method (Namaganda et al., 2015). Multi-disciplinary meetings could be conducted at a district, provincial or national level to encourage improved interaction between different health professional groups involved in HWF planning and planning, focusing on enhancing the WISN implementation process.

We have also explored the role of resource availability (funding, materials and human) and its influence on WISN implementation. There is overwhelming evidence that governments that invested in human resources for health have improved both health outcomes and economic growth (Cometto \& Campbell, 2016; World Health Organization, 2016b). However, differences in beliefs about resources availability for WISN implementation seem to reflect the different health workforces' planning practice within the facilities/organisations and across the country. Participants often reported that time constraints, lack of capacity to apply the WISN tool and high patients' workload hindered application and use of the WISN method in health workforce planning and management. Participants revealed that capacity building would have been more meaningful if they were actively involved in their learning, and learning took place in settings resembling the workplace, or the place in which they were likely to work after the capacity building process. Participants believed that interactive as well as hands-on capacity building experiences would help them to address workplace planning and management challenges, and they thought it would empower them to determine staffing requirements independently. This is in line with the view of Matovu et al., that health workforce capacity can be strengthened through work-based training or capacity building (Matovu et al., 2013).

As indicated in other studies conducted in the African region, government should ensure there is a budget and the resources (goods and services) required to ensure effective WISN implementation in place (Musua et al., 2008; Namaganda et al., 2015; World Health Organization, 2016c). Government leadership and support is vital in creating an enabling environment for effective implementation of the WISN process through HR and financial resources, as reported by Namaganda et al., wherein the importance of high-level backing from the Ministry of Health has been emphasised (Namaganda et al., 2015). Recent international literature revealed that indecisiveness and continuing underinvestment in the health and social workforce have compromised health and security, and resulted in serious economic setback (World Health Organization, 2016b). The South African Government policy makers should therefore change the way they invest in the health workforce if they are to achieve government priorities, including universal access to healthcare for all.

South Africa, like many other countries in the region, is looking for opportunities to improve efficiency in health workforce utilisation, yet health systems are impossible without adequate health workers who are the core of the health system (Chen et al., 2004). The specific nature of the PHC settings is thought to influence the success of achieving health for all (World Health Organization, 1978). The nature of the care provided at PHC settings is mainly preventative and health promotive, including curative care for minor ailments. A moratorium on staffing at PHC settings could result in a long waiting time, lack of access to healthcare services (Ravhengani \& Mtshali, 2017; World Health Organization, 2013; World Health Organization, 1978) and patients may bypass PHC facilities to seek minor healthcare at hospital level (Visser, Marincowitz, Govender, \& Ogunbanjo, 2015). Bypassing PHC settings for treatment of minor ailments results in high cost concerns (Visser et al., 2015).

These findings have potential implications on implementation, particularly in addressing whether the WISN approach can be utilised as standard approach to workforce planning at all PHC settings or needs to be area specific. This study identified elements related to WISN implementation intervening conditions and resources that impact on health workforce managers' HRH planning and management in PHC settings. Participants reported on leadership and PHC nurse management and the WISN coordinators turnover, and its impact on the stability in the provinces, including a moratorium placed on filling of vacant posts and their inability to replace staff who have either resigned or retired.

In addition, when those in key positions, which are crucial for the operations of the organisations or government, resign or retire their skills and experience may be hard to replace, which may lead to leadership crises and have a negative impact on the sustainability of programme implementation. Lessons from the study conducted in 
Uganda showed that high turnover of technical and senior managers impacted on the effectiveness of WISN implementation (Namaganda et al., 2015), however having plans, including succession planning, in place to help employees to acquire the skills and competencies required to fill the vacant positions, to address loss of institutional memory and to ensure continuity could assist greatly (Pena, 2013; Rothwell, 2010).Conversely, by developing and implementing strategies to attract and retain the health workforce, particularly in remote and rural areas, could also assist in ensuring low turnover (Dussault \& Franceschini, 2006).

The study findings also revealed that for successful implementation of the WISN process, capacity building of stakeholders is essential at the planning phase. The findings revealed that capacity building is more meaningful when they are actively involved in their learning, and learning is taking place in a setting resembling the workplace, or the place they are likely to work in after the process. This is in line with the view of Matovu et al., that health workforce capacity can be strengthened through work-based training or capacity building (Matovu et al., 2013). The interactive as well as hands-on capacity building experiences would allow PHC nurse managers to address workplace planning and management challenges and afford the opportunity to determine staffing requirements for their facilities independently.

Participants revealed lack of technical capacity as a barrier against successful WISN implementation at PHC settings. Musau supported this by reporting that the WISN required a dedicated team with adequate expertise to make the raw data meaningful for calculations (Musua et al., 2008). However, authors from different African regions did not support this finding (Burmen et al., 2017; Ly, Kouanda \& Ridde, 2014; Namaganda et al., 2015) as according to them, WISN is easy to apply with minimum training. Additionally, there is a need for continuous technical support, as well as hands-on learning experiences, to allow PHC nurse managers to determine their staffing requirements using a bottom-up approach to HRH planning (Shipp, 1998; World Health Organization, 2016c). It is important to note, and which emerged from literature, that the WISN method is an objective and reliable way of determining staffing needs (Burmen et al., 2017; Musua et al., 2008; Namaganda et al., 2015), and that successful WISN implementation facilitates health system strengthening and expands health services to underserved settings (McQuide et al., 2013; Namaganda et al., 2015).

Through the process of this study, we were able to explore the views of health workforce mangers by asking health PHC nurse managers and WISN coordinators to identify the WISN method implementation issues that would facilitate uptake of this approach in PHC settings and subsequently improve HRH planning practice. Participants expressed the need to overcome modifiable barriers and enhance enablers in order to increase the likelihood for successful WISN implementation in PHC settings in South Africa. Our study suggests that political will and leadership, provision of necessary enablers such as computer training, continuous technical support, a collaborative and consultative approach by key partners and stakeholders, clear, efficient and consistent communication, availability of resources such as funding (materials and human) and stability in leadership and PHC staff could lead to successful implementation of WISN implementation across PHC settings in South Africa. This study is one of the few that has explored the perceptions of the health workforce managers on the barriers and enablers identified.

Our study is limited by restriction to only one geographical area in a single province, however, the overarching barriers and enablers were demonstrated across both categories of HRH managers. The sample size was sufficient to facilitate further analysis to be undertaken to explore the views of both the PHC nurse managers and the WISN coordinators on the barriers and enablers identified. The results of our study may have been limited due to the significant proportion of health workforce managers who volunteered to take part; individuals may have a higher degree of interest in WISN-based health workforce planning and management compared with other health workforce managers. However, the sample size and purposeful sample method ensured that the participants were likely to be representative of the PHC facilities and province involved in the study.

Conducting the study on a larger scale across South Africa could potentially identify other barriers or enablers to implementation of the WISN method and may provide a greater understanding of the issues raised in our study. In addition, it would be useful to conduct further research on the implementation guideline of health workforce normative guides and standards for fixed PHC facilities, within the same cohort of participants to see if the barriers and enablers are related.

\section{Conclusion}

Our study identified barriers and enablers to implementing WISN method in PHC settings in South Africa, as viewed by Department of Health's HRH managers, which included PHC nurse managers and WISN coordinators. Despite the overarching barriers and enablers demonstrated across PHC settings and across provinces, there were some additional beliefs and contrary beliefs identified between the different PHC nurse managers and WISN 
coordinators. The study findings will be used to shape the WISN implementation approach to address identified barriers and enhance the recognised enablers. This study finding should facilitate the process to improve understanding on how WISN implementation programmes can be successful in order to improve health outcomes for all.

\section{Acknowledgement}

The authors wish to thank the study participants for their contribution to the research, and specifically $\operatorname{Dr}$ Zamasoni Luvuno, for her support with data collection.

\section{Competing Interest Disclosure}

The authors declare there is no conflict of interest statement.

\section{References}

Anand, S., \& Bärnighausen, T. (2012). Health workers at the core of the health system: framework and research issues. Health Policy, 105(2), 185-191. https://doi.org/10.1016/j.healthpol.2011.10.012

Brink, H.I.L. (1993). Validity and reliability in qualitative research. Curationis, 16(2), 35-38. https://doi.org/10.4102/curationis.v16i2.1396

Burmen, B., Owuor, N., \& Mitei, P. (2017). An assessment of staffing needs at a HIV clinic in a Western Kenya using the WHO workload indicators of staffing need WISN, 2011. Human Resources for Health, 15(1), 9. https://doi.org/10.1186/s12960-017-0186-3

Chen, L., Evans, T., Anand, S., Boufford, J.I., Brown, H., Chowdhury, M., \& Elzinga, G. (2004). Human resources for health: overcoming the crisis. The Lancet, 364(9449), 1984-1990. https://doi.org/10.1016/S0140-6736(04)17482-5

Chenitz, W.C., \& Swanson, J.M. (1986). Qualitative research using grounded theory. From Practice to Grounded Theory: Qualitative Research in Nursing, 3-15.

Cometto, G., \& Campbell, J. (2016). Investing in human resources for health: beyond health outcomes. Human Resources for Health, 14(1), 51. https://doi.org/10.1186/s12960-016-0147-2

Cometto, G., \& Witter, S. (2013). Tackling health workforce challenges to universal health coverage: setting targets and measuring progress. Bulletin of the World Health Organization, 91(11), 881-885. https://doi.org/10.2471/BLT.13.118810

Corbin, J., \& Strauss, A. (2003). Grounded Theory research: Procedures, canons and evaluative criteria. Interviewing, 4, 107-124.

Corbin, J., Strauss, A., \& Strauss, A.L. (2014). Basics of qualitative research. Sage.

Creswell, J.W. (2009). Research design: Qualitative, quantitative, and mixed methods research. Los Angeles, SAGE.

Department of Health. (2003). National Health Act (No. 61). Pretoria: Government Printers. Retrieved from http://www.gov.za/sites/www.gov.za/files/a61-03.pdf

Department of Health. (2015). Implementation guideline of health workforce normative guides and standards for fixed PHC facilities. Pretoria, South Africa: Government Printers.

Department of Health. (2017). National Health Insurance Policy: Towards universal health coverage. Pretoria: South Africa: Government Printers.

Dussault, G., Buchan, J., Sermeus, W., \& Padaiga, Z. (2010). Assessing future health workforce needs. World Health Organization, Copenhagen.

Dussault, G., \& Dubois, C.A. (2003). Human resources for health policies: a critical component in health policies. Human Resources for Health, 1(1), 1. https://doi.org/10.1186/1478-4491-1-1

Dussault, G., \& Franceschini, M.C. (2006). Not enough there, too many here: understanding geographical imbalances in the distribution of the health workforce. Human Resources for Health, 4(1), 12. https://doi.org/10.1186/1478-4491-4-12

Gilson, L. (2016). Everyday politics and the leadership of health policy implementation. Health Systems \& Reform, 2(3), 187-193. https://doi.org/10.1080/23288604.2016.1217367 
Govule, P., Mugisha, J.F., Katongole, S.P., Maniple, E., Nanyingi, M., \& Anguyo, R. (2015). Application of workload indicators of staffing needs (WISN) in determining health workers' requirements for Mityana General Hospital, Uganda. International Journal of Public Health Research, 3(5), 254-263.

Hongoro, C., \& McPake, B. (2004). How to bridge the gap in human resources for health. The Lancet, 364(9443), 1451-1456. https://doi.org/10.1016/S0140-6736(04)17229-2

Hongoro, C., Oliveira-Cruz, V., McPake, B., \& Ssengooba, F. (2004). Human resource studies in health for poor and transitional countries.

Jeanette, R., Hunter, T.M.C., Shaidah, A., Jeanne-Marie, T., Ntshengedzeni, M.R., \& Yvonne, M. (2017). The Ideal Clinic in South Africa: progress and challenges in implementation. South African Health Review 2017-Health Systems Trust, (20).

Ly, A., Kouanda, S., \& Ridde, V. (2014). Nursing and midwife staffing needs in maternity wards in Burkina Faso referral hospitals. Human Resources for Health, 12(1), S8. https://doi.org/10.1186/1478-4491-12-S1-S8

Matovu, J.K., Wanyenze, R.K., Mawemuko, S., Okui, O., Bazeyo, W., \& Serwadda, D. (2013). Strengthening health workforce capacity through work-based training. BMC International Health and Human Rights, 13(1), 8. https://doi.org/10.1186/1472-698X-13-8

McQuide, P.A., Kolehmainen-Aitken, R.L., \& Forster, N. (2013). Applying the workload indicators of staffing need (WISN) method in Namibia: challenges and implications for human resources for health policy. Human Resources for Health, 11(1), 64. https://doi.org/10.1186/1478-4491-11-64

Mtshali, N.G. (2009). Implementing community-based education in basic nursing education programmes in South Africa. Curationis, 32(1), 25-32. https://doi.org/10.4102/curationis.v32i1.870

Musua, P., Nyongesa, P., Shikhule, A., Birech, E., Kirui, D., Njenga, M., \& Kiilu, K. (2008). Workload Indicators Of Staffing Need Method in determining optimal staffing levels at Moi Teaching and Referal Hospital. East African Medical Journal, 85(5), 232-239. https://doi.org/10.4314/eamj.v85i5.9617

Namaganda, G., Oketcho, V., Maniple, E., \& Viadro, C. (2015). Making the transition to workload-based staffing: using the Workload Indicators of Staffing Need method in Uganda. Human Resources for Health, 13(1), 89. https://doi.org/10.1186/s12960-015-0066-7

Omaswa, F., \& Boufford, J.I. (2010). Strong ministries for strong health systems. A Strategy for Health Systems Strengthening: Supporting Ministerial Health Leadership.

Pena, A.M. (2013). Institutional knowledge: When employees leave, what do we lose. Higher Ed Jobs.

Polit, D.F., \& Beck, C.T. (2012). Resource manual for nursing research. Wolters Kluwer Health/lippincott Williams \& Wilkins.

Puras, D. (2016). Universal health coverage: a return to Alma-Ata and Ottawa. Health and Human Rights, 18(2), 7.

Ravhengani, N.M., \& Mtshali, N.G. (2017). Implementing Workload Indicators of Staffing Need (WISN) Tool to Determine Human Resources in Primary Health Care Settings in South Africa: A Concept Analysis. IOSR Journal of Nursing and Health Science (IOSR-JNHS), 6(6), 65-73. https://doi.org/10.9790/1959-0606056573

Rawaf, S., De Maeseneer, J., \& Starfield, B. (2008). From Alma-Ata to Almaty: a new start for primary healthcare. The Lancet, 372(9647), 1365-1367. https://doi.org/10.1016/S0140-6736(08)61524-X

Rothwell, W.J. (2010). Effective succession planning: Ensuring leadership continuity and building talent from within. AMACOM Div American Mgmt Assn.

Shenton, A.K. (2004). Strategies for ensuring trustworthiness in qualitative research projects. Education for Information, 22(2), 63-75. https://doi.org/10.3233/EFI-2004-22201

Shipp, J. (1998). Guidelines for developing and using workload indicators of staffing need. Geneva: World Health Organization.

Snyder, L., Hamilton, M., \& Hornik, R.C. (2002). Public health communication: evidence for behavior change. Public Health Communication: Evidence for Behavior Change.

Strauss, A., \& Corbin, J. (1990). Basics of qualitative research (Vol. 15). Newbury Park, CA: Sage. 
Tufford, L., \& Newman, P. (2012). Bracketing in qualitative research. Qualitative social work, 11(1), 80-96. https://doi.org/10.1177/1473325010368316

Valente, T.W., Palinkas, L.A., Czaja, S., Chu, K.H., \& Brown, C.H. (2015). Social network analysis for program implementation. PloS one, 10(6). https://doi.org/10.1371/journal.pone.0131712

Vio, F. (2010). Applying the WISN method in Nampula and Sofala Provinces, Mozambique, 2004. Applying the WISN Method in PRACTICE: Case Studies From Indonesia, Mozambique and Uganda, 10-17.

Visser, C., Marincowitz, G., Govender, I., \& Ogunbanjo, G. (2015). Reasons for and perceptions of patients with minor ailments bypassing local primary healthcare facilities. South African Family Practice, 57(6), 333-336. https://doi.org/10.1080/20786190.2015.1102538

World Health Organisation. (2013). A Universal Truth: No Health without a workforce. Geneva, Switzerland: World Health Organization.

World Health Organization. (1978, September). Declaration of Alma-Ata: International Conference on Primary Healthcare, Alma-Ata, USSR, 6-12.

World Health Organization. (2006). The World Health Report: working together for health. Geneva, Switzerland: World Health Organization.

World Health Organization. (2007). Everybody's business-strengthening health systems to improve health outcomes: WHO's framework for action. Geneva, Switzerland: World Health Organization.

World Health Organization. (2010). Workload Indicators of Staffing Need (WISN). G Geneva, Switzerland: World Health Organization.

World Health Organization. (2015). The World Health Report 2008: primary healthcare now more than ever. 2008. Geneva, Switzerland: World Health Organization.

World Health Organization. (2016a). Global strategy on human resources for health: workforce 2030. G Geneva, Switzerland: World Health Organization.

World Health Organization. (2016b). High-level commission on health employment and economic growth. report of the expert group.

World Health Organization. (2016c). Workload indicators of staffing need (WISN): selected country implementation experiences. Geneva, Switzerland: World Health Organization.

\section{Copyrights}

Copyright for this article is retained by the author(s), with first publication rights granted to the journal.

This is an open-access article distributed under the terms and conditions of the Creative Commons Attribution license (http://creativecommons.org/licenses/by/4.0/). 